\title{
Investigation on the determination feasibility of the non-parallelity of the gravity field equipotential surfaces
}

\author{
Petras Petroskevicius ${ }^{\mathrm{a}}$, Rosita Birvydiene ${ }^{\mathrm{a}, \mathrm{b}}$, Romuald Obuchovski ${ }^{\mathrm{b}}$ \\ ${ }^{a}$ Department of Geodesy and Cartography, Vilnius Gediminas technical university, Sauletekio av. 11, Vilnius 10223, Lithuania \\ ${ }^{b}$ Institute of Geodesy, Vilnius Gediminas technical university, Sauletekio av. 11, Vilnius 10223, Lithuania
}

\begin{abstract}
Geodetic measurements are performed in heterogeneous gravity field. Its equipotential surfaces have a complex shape. This needs to be estimated when processing detail geodetic measurements data. Orthometric heights are calculated from one of the equipotential surface geoid. Applying the normal height system and evaluating normal height differences needs to assess the non-parallelity of the equipotential surfaces of the gravity field. For that aim normal corrections, defining the non-parallelity of equipotential surfaces of normal gravity field and the deviation of the equipotential surfaces of real gravity field from the normal field are calculated. This work presents determination feasibility of the gravity field equipotential surfaces non-parallelity in Lithuanian territory. The six geodetic vertical network lines were selected for a research; the length of all lines is about $300 \mathrm{~km}$. The gravimetric measurements by Scintrex CG-5 were performed at 203 points of the net. A mean square error of gravity acceleration values did not exceed $14 \mu \mathrm{Gal}$. The normal corrections were calculated for measured height differences between points. A research shows that after reduction of a number of measured points twice, a mean square error of gravity acceleration values, calculated from interpolated Bouguer gravity anomalies, at the "not measured" points seeks 0.474 $\mathrm{mGal}$, however the normal correction values have changed only in $0.01 \mathrm{~mm}$. The use of gravity acceleration values, obtained from gravimetric map with the mean square error of $0.684 \mathrm{mGal}$, changes normal corrections up to $0.04 \mathrm{~mm}$.
\end{abstract}

Keywords: Non-parallelity; equipotential surface; normal correction.

\begin{tabular}{|ll|}
\hline \multicolumn{2}{|l|}{ Nomenclature } \\
$f_{i k}$ & normal correction, $m m$ \\
$m_{14}$ & mean square error according gravimetric map, $m G a l$ \\
$m_{z z}$ & mean square error according a digital model of corrections, $m G a l$ \\
$g_{P 14}$ & gravity acceleration after the correction of $14 \mathrm{mGal}$ \\
$g_{z z}$ & gravity acceleration after the correction $d g s$ \\
$d g s$ & correction from digital gravimetric map model \\
$1 \mathrm{mGal}=10^{-5} \mathrm{~m} / \mathrm{s}^{2}$
\end{tabular}

\section{Introduction}

Geodetic measurements are performed in heterogeneous gravity field. Gravity field lines are of double curvature, and the equipotential surfaces have a complex shape. Geodetic measurements are related to the gravity field. Orthometric heights are calculated from one of the equipotential surface - geoid. Prior processing geodetic measurements first needs to reduce them to a uniform coordinate system considering the non-homogeneity of the gravity field. In geodesy a gravity field is divided into the normal gravity field which is selectable and disturbed gravity field, which expresses the real gravity field deviation from the normal. Therefore the assessment of normal gravity field non-homogeneity is required. Mostly general equipotential ellipsoid of the Earth is used as a normal gravity field, the geodetic heights are determined from it. Choosing the normal height system and evaluating normal height differences needs to assess the non-parallelity of the equipotential surfaces of the gravity field. Increasing the accuracy of geodetic measurements requires a more accurate assessment of non-

Corresponding author: Rosita Birvydiene. E-mail address: rosita.birvydiene@vgtu.lt

http://dx.doi.org/10.3846/enviro.2014.238

(C) 2014 The Authors. Published by VGTU Press. This is an open-access article distributed under the terms of the Creative Commons Attribution License, which permits unrestricted use, distribution, and reproduction in any medium, provided the original author and source are credited. 
parallelity of the equipotential surfaces. It is important for the development of modern geodetic basis [1, 2], establishment of geodetic networks [3,4], geodetic works in unique objects (hydrotechnical equipment, tunnels, elementary particle accelerators, etc.) in the period of their construction and operation. Quality of the geodynamic and geophysical research also depends on an accuracy of surveying. This paper presents various options for evaluation of the non-parallelity of the gravity field equipotential surfaces in Lithuanian territory.

\section{Evaluation of non-parallelity of equipotential surfaces}

When determining a non-parallelity of gravity field equipotential surfaces, both normal gravity field equipotential surfaces non-parallelity and misalignment of equipotential surfaces of real gravity field and normal gravity field are evaluated. Currently many countries also Lithuania use the normal gravity field GRS80 [5, 6], where normal gravity is defined as follows in Eqn (1).

$$
\gamma_{0}=\gamma_{e} \frac{1+k \sin ^{2} B}{\sqrt{1-e^{2} \sin ^{2} B}}
$$

here $k=\frac{b \gamma_{p}}{a \gamma_{e}}-1$; semimajor axis of equipotential ellipsoid $a=6378137 \mathrm{~m}$; semiminor axis of equipotential ellipsoid $b=6356752.3141 \mathrm{~m}$; normal gravity at the equator of ellipsoid $\gamma_{e}=978032.67715 \mathrm{mGal}$; normal gravity at the poles of ellipsoid $\gamma_{p}=983218.63685 \mathrm{mGal} ; B-$ LKS 94 system geodetic latitude; first excentricity of ellipsoid $e$, $e^{2}=0.00669438002290 ; k=0.001931851353$.

A misalignment of equipotential surfaces of real and normal gravity field between two points $f_{1 i k}$ depends on gravity anomalies and is defined as follows [6]

$$
f_{1 i k}=\frac{1}{\gamma_{v}}(g-\gamma)_{v} h_{i k}
$$

here $\gamma_{v}$-average normal gravity acceleration between ellipsoid and teluroid (it is assumed that in the territory of Lithuania $\left.\gamma_{v}=981500 \mathrm{mGal}\right) ;(g-\gamma)_{v}-$ average free-air gravity anomaly at a point, $(g-\gamma)_{v}=\frac{1}{2}\left[(g-\gamma)_{i}+(g-\gamma)_{k}\right] ; h_{i k}-$ measured height difference.

Combined free-air gravity anomaly is defined as follows in Eqn (3),

$$
(g-\gamma)=g-\gamma_{0}+\Delta \gamma(H)+\Delta g_{a}(H)
$$

here $g$ - LSS07 system gravity acceleration on the Earth surface; $H$ - LVS07 system normal height of the Earth surface;

$$
\Delta \gamma(H)=0,30877\left(1-0,00142 \sin ^{2} B\right) H-0,75 \cdot 10^{-7} H^{2}
$$

- height correction of GRS 80 normal gravity field, mGal ( $H$ in meters) [7];

$$
\Delta g_{a}(H)=0,874-0,99 \cdot 10^{-4} H+0,356 \cdot 10^{-8} H^{2}
$$

- atmospheric correction of attraction, mGal.

Non-parallelity of normal gravity field equipotential surfaces between points $i$ and $k$ is defined as [6]

$$
f_{2 i k}=-\frac{1}{\gamma_{v}}\left(\gamma_{0 k}-\gamma_{0 i}\right) H_{v}
$$

Normal correction $f_{i k}$ evaluates non-parallelity of gravity field equipotential surfaces and is used to get from measured height difference to normal height difference. The formula used to calculate normal correction is written down below in Eqns (7-8):

$$
\begin{gathered}
f_{i k}=f_{1 i k}+f_{2 i k} \\
f_{i k}=\frac{1}{\gamma_{v}}(g-\gamma)_{v} h_{i k}-\frac{1}{\gamma_{v}}\left(\gamma_{0 k}-\gamma_{0 i}\right) H_{v}
\end{gathered}
$$

Investigation on the determination feasibility of the normal corrections using various gravimetric data is performed. The points of six $2^{\text {nd }}$ order geodetic vertical network lines over all Lithuania (Fig. 1), where gravimetric measurements had been carried out, were selected for research. The information from a map of Bouguer gravity anomaly was also used for determination of normal corrections. 


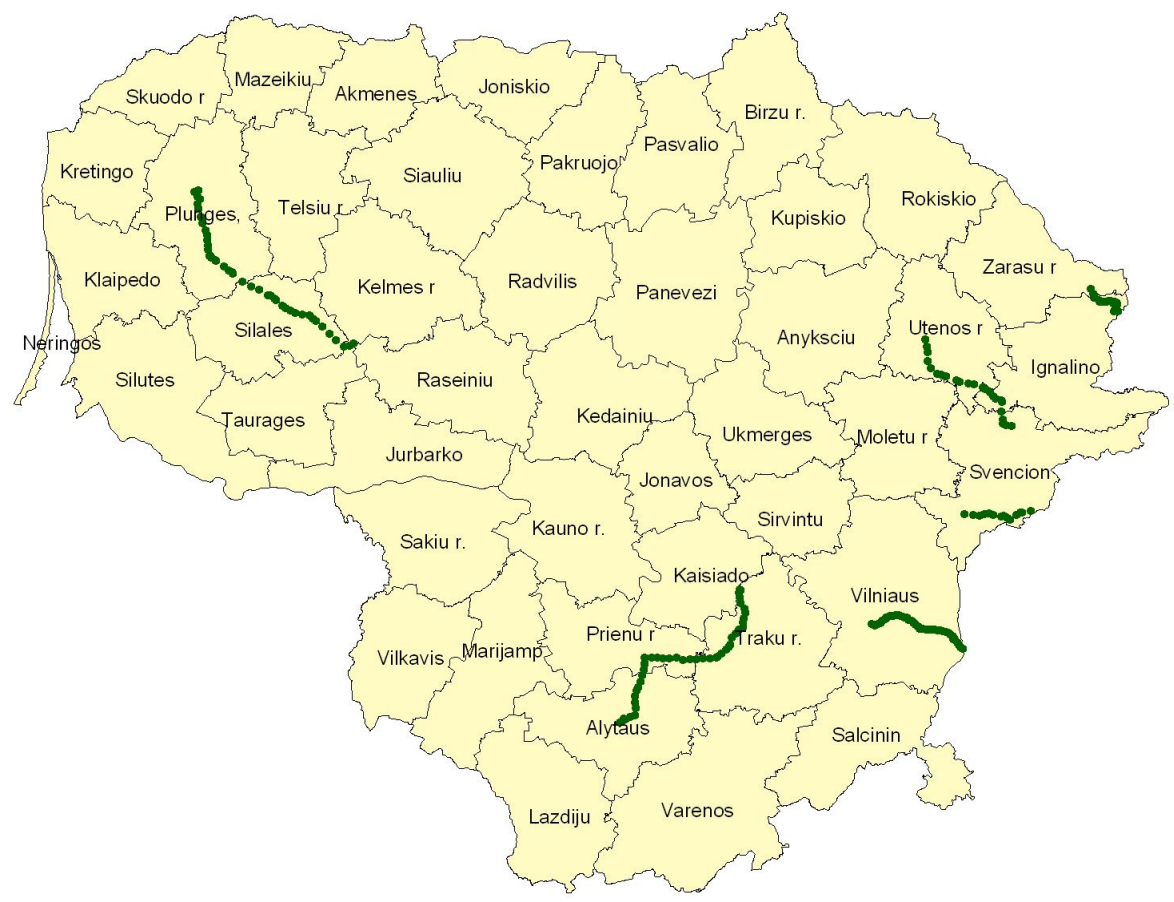

Fig. 1. Vertical network lines used for research

Overall distance of lines used for research is about $300 \mathrm{~km}$. Average distance between points is about $1.5 \mathrm{~km}$.

\section{The use of data from gravimetric survey}

Gravimetric measurements were performed in 203 points by two automatic quartz gravimeters Scintrex CG-5. A mean square error of gravity acceleration values $g_{z}$ obtained at the point does not exceed $14 \mu \mathrm{Gal}$. The calculation of normal corrections was performed in all lines. The values of normal corrections do not exceed $0.53 \mathrm{~mm}$. The range of all corrections is shown in Figure 2.

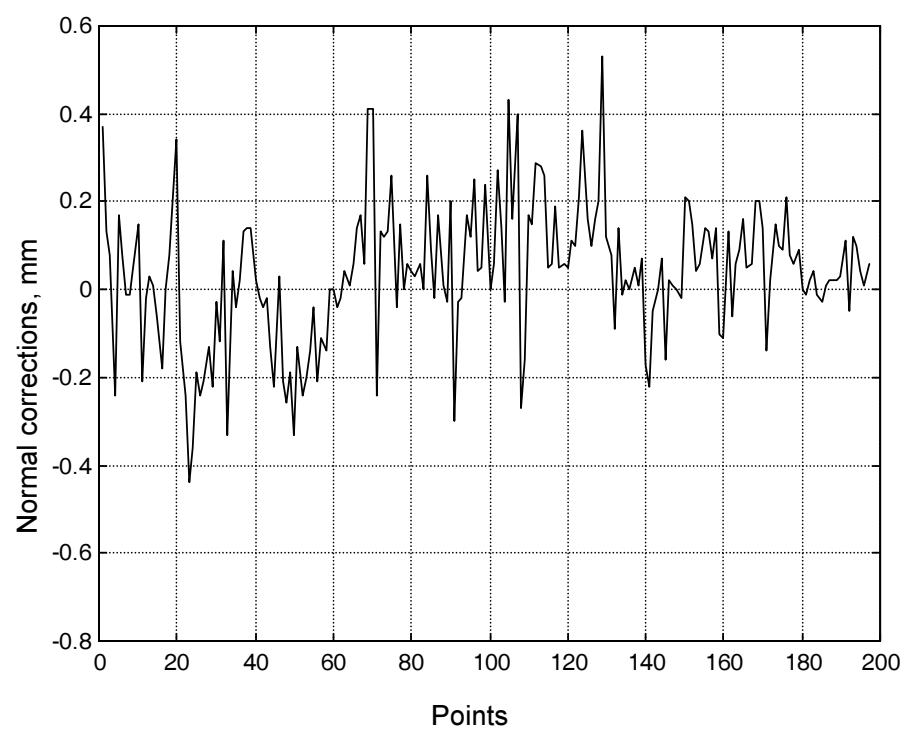

Fig. 2. Normal corrections, $\mathrm{mm}$

At first at the points of line Alytus - Elektrenai normal corrections were calculated in all points where gravimetric observations had been performed, then the number of points was reduced from 49 to 23 (about 2.1 times) for the same calculations. An average distance between points with observed gravity acceleration is $3.40 \mathrm{~km}$ ( $21 \mathrm{chords})$. At the points, that had been accepted as without gravity observations, the gravity acceleration was calculated from the interpolated values of Bouguer anomalies. The difference between observed and calculated gravity acceleration values exceed to $1.17 \mathrm{mGal}$ (Fig. 3). 


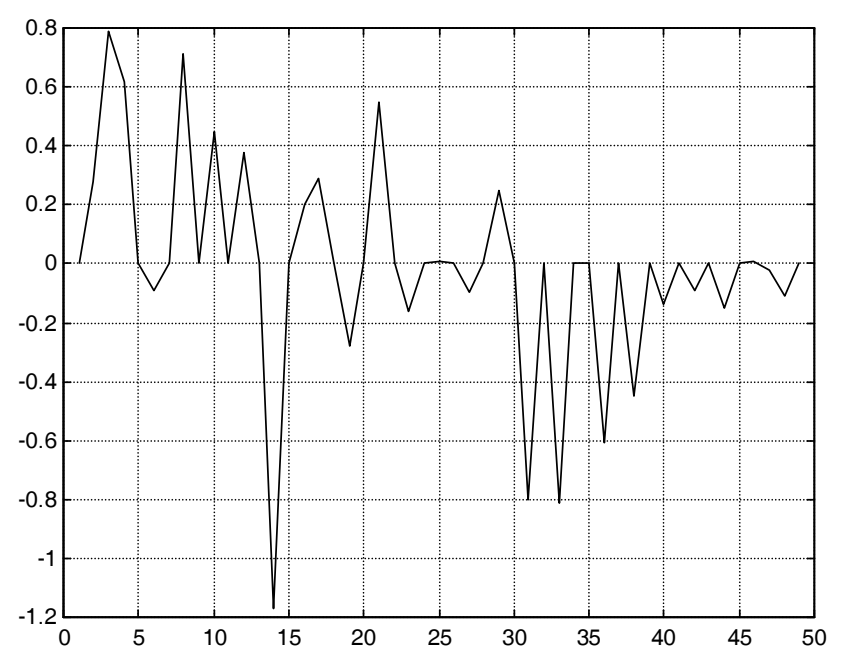

Fig. 3. The difference of gravity acceleration values

A mean square error of gravity acceleration values obtained from calculation is $0.474 \mathrm{mGal}$. Normal corrections were calculated using gravity acceleration values obtained by above mentioned way. The difference from corrections, obtained only from gravimetric observations, was up to $0.01 \mathrm{~mm}$.

\section{A use of the gravimetric Bouguer anomaly map}

The gravimetric Bouguer anomaly map of Lithuanian territory in scale of 1:200 000, based on gravimetric survey of the period 1954-1959 [6] could be used to evaluate the non-parallelity of equipotencial surfaces. During processing of gravimetric survey the Potsdam gravity system was used. The map was formed and published in 1963-1976. The coordinate system of 1942, the Krassovski ellipsoid and Baltic normal height system were used for mapping. The Helmert's formula for the estimation of normal field and the density of the Earth's crust $\delta=2.3 \mathrm{~g} / \mathrm{cm}^{3}$ were used for calculations of the anomalies. The gravimetric field of Bouguer anomalies on the map is presented by isolines at every 2 mGal. All the points of gravimetric survey were presented in the map with gravimetric Bouguer anomalies at each point.

Depending on isolines of Bouguer gravity anomalies the interpolation of values was performed in order to get the gravity acceleration at the points of geodetic vertical network. The gravity acceleration $g_{P}$ of Potsdam gravity system was calculated according to formulae below:

$$
g_{P}=\left(g_{P}-\gamma_{H}\right)+\gamma_{H}^{0}-0.3086 H_{B}
$$

here $\left(g_{P}-\gamma_{H}\right)=\left(g_{P}-\gamma_{H}\right)_{\delta}+0,0419 \delta H_{B}$ combined free-air gravity anomaly;

$g_{P}$ - gravity acceleration of Potsdam gravity system; $\gamma_{H}^{0}-$ the Helmert's normal gravity field acceleration on the surface of equipotential ellipsoid

$$
\gamma_{H}^{0}=978030\left(1+0.005302 \sin ^{2} B_{42}-0.000007 \sin ^{2} 2 B_{42}\right)
$$

$B_{42}$ - geodetic latitude in coordinate system of 1942; $H_{B}$ - the normal height of the point on the Earth surface in Baltic system in meters. IGSN 71 system gravity acceleration $g_{P 14}$ is calculated according to formula below:

$$
g_{P 14}=g_{P}-14
$$

Also the gravity acceleration values were determined using the model of gravimetric map corrections. This model was designed according to data of Lithuanian gravimetric network [8,9]. The gravity acceleration values were assessed by formula:

$$
g_{z z}=g_{P}-d g s
$$

here $d g s$ - the correction from digital gravimetric map model.

Using both gravimetric map and a digital model of gravimetric map corrections data gravity acceleration was determined for all 203 points. The obtained mean square errors ( $m_{14}-$ according gravimetric map, $m_{z z}-$ according a digital model of corrections) of gravity acceleration values at every line are represented in Table 1. 
Table 1 . The mean square errors of gravity acceleration

\begin{tabular}{llll}
\hline No & Line name & $m_{14}$ & $m_{z z}$ \\
\hline 1 & Pabrade_Geledne & 1.053 & 0.725 \\
2 & Alytus_Elektrenai & 0.651 & 0.529 \\
3 & Plunge_Stulgiai & 0.856 & 0.337 \\
4 & Utena_Svencioneliai & 0.611 & 0.624 \\
5 & Vilnius_Sumskas & 0.360 & 0.463 \\
6 & Visaginas_Varniskiai & 0.580 & 0.434 \\
\hline
\end{tabular}

General estimation of an accuracy of gravity acceleration in all points results in $m_{14}=0.684 \mathrm{mGal}, m_{z z}=0.497 \mathrm{mGal}$. Thus using digital model of corrections for determination of gravity acceleration values resulted in reduction of mean square errors about 1.4 times as compared with the mean square errors of gravity acceleration obtained from gravimetric map.

Errors of normal corrections of $0.04 \mathrm{~mm}$ were obtained using gravimetric map data and they have been reduced to $0.03 \mathrm{~mm}$ when digital model of corrections is used.

\section{Conclusions}

- Using data of gravimetric measurements performed in $2^{\text {nd }}$ order geodetic vertical network it was achieved that after reduction a number of measured points twice (an average distance between points with observed gravity acceleration is $3.40 \mathrm{~km}$ ) a mean square error of gravity acceleration values calculated from interpolated Bouguer gravity anomalies is $0.474 \mathrm{mGal}$. However using these values for calculating the normal corrections, defining the non-parallelity of equipotential surfaces of gravity field, the correction values changed only in $0.01 \mathrm{~mm}$.

- According to results of gravimetric survey performed at 203 points of geodetic vertical network it was assessed that a mean square error of gravity acceleration values derived from gravimetric map is $0.684 \mathrm{mGal}$. A mean square error of the values of gravity acceleration obtained from gravimetric map and corrected with digital correction model reduces to $0.497 \mathrm{mGal}$. Using values of gravity acceleration obtained in such a way for calculation of normal corrections a mean square error amounts $0.03-0.04 \mathrm{~mm}$.

\section{References}

[1] Sacher, M.; Ihde, J.; Liebsch, G.; Mäkinen, J. 2009. EVRF2007 as the realization of the European Vertical Reference System, Boll. Geod. Sci. Aff. LXVIII (1): 35-50.

[2] Bilker-Koivula, M. 2010. Development of the Finnish height conversion surface FIN2005N00, Nordic Journal of Surveying and Real Estate Research 7(1): 76-88.

[3] Aleksejenko, I.; Sakne, J.; Kalinka, M.; Reiniks, M.; Kalantaite, A.; Krikštaponis, B.; Paršeliūnas, E.; Petroškevičius, P.; Viskontas, P. 2012. The united geodetic vertical network of Latvia and Lithuania, Geodezija ir kartografija [Geodesy and cartography] 38(1) : 9-19. Available from Internet: http://www.tandfonline.com/doi/pdf/10.3846/20296991.2012.679800.

[4] Paršeliūnas, E.; Petroškevičius, P.; Obuchovski, R.; Birvydiené, R. 2013. An investigation of the automatic relative gravimeters, Mechatronic Systems and Materials V. Solid State Phenomena 199: 261-266. Switzerland : Trans Tech Publications Ltd. ISBN 9783037856451 Available from Internet: http://www.ttp.net/978-3-03785-645-1/toc.html.

[5] Moritz, H. 1984. Geodetic Reference System 1980, Bull. Géod. 58(3): 388-398.

[6] Petroškevičius, P. 2004. Gravitacijos lauko poveikis geodeziniams matavimams [The impact of the gravity field on the geodetic measurements]: monograph. Vilnius: Technika. 290 p. ISBN 9986057388.

[7] Torge, W. 1989. Gravimetry. Berlin, New Tork: W. de Gruyter. 465 p.

[8] Birvydienè, R.; Obuchovski, R.; Paršeliūnas, E.; Petroškevičius, P.; Šlikas, D.; Viskontas, P. 2009. Lietuvos gravimetrinio tinklo charakteristikos [The characteristics of the Lithuanian gravimetric network], Geodezija ir kartografija [Geodesy and cartography] 35(4): 131-136.

[9] Birvydienè, R.; Krikštaponis, B.; Obuchovski, R.; Paršeliūnas, E.; Petroškevičius, P.; Šlikas, D. 2010. Lietuvos teritorijos gravimetrinio žemėlapio tikslumo vertinimas [The evaluation of the accuracy of the gravimetric map of Lithuanian territory], Geodezija ir kartografija [Geodesy and cartography] 36(1): 20-24. Available from Internet: http://www.tandfonline.com/doi/pdf/10.3846/gc.2010.03. 